\title{
A VIOLÊNCIA E SEUS IMBRICAMENTOS COM O CAMPO DA SAÚDE MENTAL: UMA REVISÃO INTEGRATIVA DA LITERATURA
}

\section{Ricardo Otávio Maia Gusmão}

Enfermeiro. Mestre em Teoria Psicanalítica pela Universidade Federal do Rio de Janeiro (UFRJ). Docente efetivo de educação superior. Brasil.

\section{Suelen Ferreira Rocha}

Enfermeira pela Universidade Estadual de Montes Claros (UNIMONTES), Brasil.

\section{Andréia Tatielli Alves Urcino}

Acadêmica de Medicina pela Universidade Estadual de Montes Claros (UNIMONTES), Brasil.

\section{Bruna Stefany Ribeiro Souza}

Acadêmica de Medicina pela Universidade Estadual de Montes Claros (UNIMONTES), Brasil.

\section{Mariza Dias Xavier}

Acadêmica de Medicina pela Universidade Estadual de Montes Claros (UNIMONTES), Brasil.

\section{Letícia Ferreira Alkimim Ladeia}

Enfermeira pela Universidade Estadual de Montes

\section{Renê Ferreira da Silva Junior}

Enfermeiro. Mestre em Ensino e Saúde Universidade Federal dos Vales do Jequitinhonha e Mucuri. Docente de educação superior. Brasil. Claros (UNIMONTES), Brasil.

RESUMO: O presente estudo teve como objetivo discutir sobre os imbricamentos existentes entre o fenômeno da violência e o campo da saúde mental a partir de uma revisão integrativa da literatura brasileira sobre a temática. Propôs-se investigar o fenômeno violência e sua relação com a produção de sofrimento psíquico, verificar qual a relação existente entre o cometimento da violência e sua causalidade manifestada pela presença de transtornos mentais e uso de drogas e pesquisar sobre as principais formas de vitimização sofridas por portadores de sofrimento mental. Foi realizada busca na base de dado da Biblioteca Virtual da Saúde (BVS) identificando-se 426 artigos elegíveis para o estudo, que após análise dos critérios de inclusão resultaram em 15 artigos. Os resultados foram apresentados por meio de um quadro descritivo e, em seguida, discutidos em três categorias. Verificou-se que existe relação importante entre a vivência das diversas situações de violência e como consequência a produção de sofrimento psíquico e ocorrência de transtornos mentais.

PALAVRAS-CHAVE: Violência; Saúde mental; Transtorno mental.

\section{VIOLENCE AND ITS RELATIONSHIPS WITH MENTAL HEALTH: AN INTEGRAL REVIEW OF THE LITERATURE}

ABSTRACT: Overlaying relationships between the phenomenon of violence and the mental health field are discussed from the integral review of literature published in Brazil. Violence and its relationship with the production of psychic sufferings are investigated, coupled to the relationship between the practice of violence and its causality manifested in mental disorders and illicit drug use. Research also comprises the main types of victimization suffered by people with mental pain. Research in the Virtual Health Library (BVS) identified 426 articles for current analysis, out of which fifteen were selected, after applying inclusion criteria. Results were given by a descriptive table and discussed under three categories. There is a relevant relationship between experiences of several situation of violence and the production of psychic suffering and the occurrence of mental disorders.

KEY WORDS: Violence; Mental health; Mental disorders.

\section{INTRODUÇão}

O termo "violência" é usado e empregado comumente em

Autor correspondente

Cristal Ribeiro Mesquita

cristalmesquita@yahoo.com.br publicações científicas e no contexto da saúde como sinônimo de "maus-tratos". O Ministério da Saúde (MS) adota o conceito de violên- 
cia utilizado pela Organização Mundial da Saúde (OMS) segundo o qual "violência é o uso intencional da força física ou do poder, contra si próprio, contra outra pessoa, ou contra um grupo ou uma comunidade, que resulte ou tenha grande possibilidade de resultar em lesão, morte, dano psicológico, deficiência de desenvolvimento ou privação"1.

Segundo o modelo proposto pela OMS, a violência se classifica em três grandes categorias: as formas autoprovocadas ou violência praticada contra si mesmo que incluem as tentativas de suicídio e o suicídio; a interpessoal provocada por indivíduos incluindo a dinâmica intrafamiliar e comunitária e a forma coletiva de violência resultante de organizações maiores que envolvem a esfera social, política e econômica ${ }^{1}$. Sobre a natureza, pode se apresentar sob a forma de violência física, sexual, psicológica ou negligência/abandono ${ }^{1}$.

Na área da saúde, a identificação dos tipos de violência e sua natureza apontam para a possibilidade de planejamento de ações de prevenção e implementação de linhas de cuidados que visem ao atendimento integral às vítimas e também aos agressores.

A violência pode ser considerada como um problema de saúde pública no mundo. Entre as causas externas, ocupa o segundo lugar em causas de morte no Brasil. Neste sentido, compreender seu conceito e seus mecanismos intrínsecos que mais afetam os seres humanos é imprescindível para reduzir os seus impactos ${ }^{2}$.

No campo da saúde mental, a violência se impõe de diversas formas requerendo debates em sua agenda. Estritamente relacionada ao campo das políticas públicas na saúde mental, a violência aparece associada à produção de sofrimento psíquico convergindo em demandas clínicas destes sujeitos que procuram os serviços de saúde por vivenciarem a experiência da violência ${ }^{3}$.

Entre as formas de violência produtoras de sofrimento psíquico, as mais presentes são as agressões intrafamiliares físicas, sexuais e psicológicas, além dos maus tratos e ameaças ${ }^{3}$.

Outra temática para debate da violência no campo da saúde mental é o imaginário social que estabelece a relação entre a violência ou risco de periculosidade com o campo da psiquiatria e saúde mental numa relação de causalidade ${ }^{3}$.

Para alguns estudos, grande parcela da popula- ção aceita a ideia de que pessoas com transtorno mental, dentre eles, por exemplo, as esquizofrenias possuem maior probabilidade de serem violentas que a população em geral ${ }^{3}$. Também é possível na contemporaneidade, a discussão que associa o uso de drogas à violência ${ }^{4}$. Outros estudos, no entanto, revelam que a violência atribuída a esse grupo é muito pequena ${ }^{5-6}$.

$\mathrm{Na}$ vida cotidiana, evidenciamos que a ocorrência de eventos relacionados à violência que tenha grande repercussão na mídia, por exemplo, é atribuída, em sua causalidade com a presença dos transtornos mentais ${ }^{3}$. Grande parte desse pensamento se deve à cultura, que desde o século XIX associa violência à "loucura" .

Por fim, gostaríamos de destacar que o portador de sofrimento mental também é vítima de violência mediante diversas formas. Destacamos na esfera social, a exclusão social e a negação de exercício de seus direitos ${ }^{3}$. A violência também está associada às barreiras de acesso ao tratamento a estes sujeitos ${ }^{4}$.

Diante do exposto, motivamo-nos entender melhor o fenômeno da violência e sua relação com o campo da saúde mental por meio do estudo das produções científicas existentes sobre a temática.

Assim, a presente pesquisa tem por objetivo discutir sobre os imbricamentos existentes entre o fenômeno da violência e o campo da saúde mental a partir de uma revisão integrativa da literatura brasileira sobre a temática. Propõe-se investigar o fenômeno violência e sua relação com a produção de sofrimento psíquico; verificar qual a relação existente entre o cometimento da violência e sua causalidade manifestada pela presença de transtornos mentais e uso de drogas e investigar sobre as principais formas de vitimização sofridas por portadores de sofrimento mental.

\section{METODOLOGIA}

Para responder aos objetivos do presente estudo, optou-se por realizar uma revisão integrativa da literatura, que é um método específico de revisão que possibilita a análise e síntese do conhecimento sobre determinado fenômeno em particular ou problema de saúde.

A revisão integrativa é um meio essencial no pro- 
cesso de transmissão dos resultados de pesquisas realizadas, a fim de promover sua utilização na prática clínica. Tal metodologia proporciona um resumo do conhecimento já produzido e provê subsídios para o progresso da assistência à saúde. Oferece também aos profissionais da área da saúde o acesso rápido aos resultados relevantes de pesquisas que se baseiam nas condutas ou a tomada de decisão, resultando em um saber crítico ${ }^{7}$.

A coleta de dados e levantamento bibliográfico foi realizada no mês de outubro de 2016, a partir da base de dado da Biblioteca Virtual da Saúde (BVS) (Quadro 1). A estratégia de busca foi efetuada por meio de estudos da literatura brasileira com corte temporal de dez anos e da combinação dos seguintes descritores: "saúde mental and violência", "transtornos mentais and violência".

Dessa forma, foram identificadas 426 publicações elegíveis para a inclusão nessa revisão. Para selecionar as publicações foram estabelecidos como critérios de inclusão: artigos que abordavam a temática violência e saúde mental e atendiam aos objetivos deste estudo, textos completos e que apresentavam disponibilidade em língua portuguesa e que compreendiam o ano de publicação de 2006 a 2016. Foram excluídos resumos e artigos em línguas estrangeiras.

Quadro 1. Sistematização da busca eletrônica

\begin{tabular}{ccccc}
\hline Banco de dados & Descritores & Artigos encontrados & $\begin{array}{c}\text { Artigos } \\
\text { selecionados }\end{array}$ & $\begin{array}{c}\text { Amostra } \\
\text { final }\end{array}$ \\
\hline BVS & $\begin{array}{c}\text { "Saúde mental } \\
\text { and violência" }\end{array}$ & 301 & 11 & 11 \\
\hline BVS & $\begin{array}{c}\text { "Transtornos mentais and vio- } \\
\text { lência" }\end{array}$ & 125 & 4 & 4 \\
\hline & Total & 426 & 15 & 15 \\
\hline
\end{tabular}

A seleção dos textos foi realizada após leitura atentiva de seus resumos por um dos autores, mediante os critérios de elegibilidade, posteriormente à seleção efetuada pela estratégia de busca. Dessa forma, foram selecionadas 15 publicações por atenderem os critérios anteriormente descritos. Inicialmente os artigos selecionados foram organizados na perspectiva de caracterizar as publicações e a abordagem temática estudada.

Os artigos selecionados foram descritos a partir do ano, da identificação do estudo, tipo de estudo e objetivo da pesquisa (Quadro 2). Em seguida, os resultados foram apresentados e discutidos em categorias.

\section{RESULTADOS}

Apresentamos o Quadro 2 que traz uma síntese das principais características dos artigos utilizados na discussão desta revisão de literatura. Em seguida, apresentaremos as categorias produzidas nessa revisão para responder aos objetivos dessa pesquisa.
Quadro 2. Estudos sobre violência e problemas de saúde mental

(Continua)

\begin{tabular}{|c|c|c|c|}
\hline Ano & Título & $\begin{array}{l}\text { Tipo de } \\
\text { estudo }\end{array}$ & Objetivo \\
\hline 2007 & $\begin{array}{l}\text { Esquizofrenia, } \\
\text { psicopatologia e } \\
\text { crime violento: } \\
\text { uma revisão das } \\
\text { evidências empí- } \\
\text { ricas. }\end{array}$ & $\begin{array}{l}\text { Revisão } \\
\text { de litera- } \\
\quad \text { tura }\end{array}$ & $\begin{array}{l}\text { Estudar, mediante uma } \\
\text { revisão sistemática da } \\
\text { literatura científica, a re- } \\
\text { lação entre esquizofrenia, } \\
\text { psicose e violência. }\end{array}$ \\
\hline 2009 & $\begin{array}{l}\text { Exposição à vio- } \\
\text { lência e problemas } \\
\text { de saúde mental } \\
\text { em países em } \\
\text { desenvolvimento: } \\
\text { uma revisão da } \\
\text { literatura. }\end{array}$ & $\begin{array}{l}\text { Revisão } \\
\text { de litera- } \\
\text { tura }\end{array}$ & $\begin{array}{l}\text { Estudar os achados } \\
\text { epidemiológicos sobre a } \\
\text { prevalência de exposição } \\
\text { à violência e a associação } \\
\text { entre exposição à violên- } \\
\text { cia e problemas de saúde } \\
\text { mental em países em } \\
\text { desenvolvimento. }\end{array}$ \\
\hline 2010 & $\begin{array}{l}\text { Fatores de risco } \\
\text { para problemas } \\
\text { de saúde mental } \\
\text { na infância-adoles- } \\
\text { cência. }\end{array}$ & $\begin{array}{l}\text { Quantita- } \\
\text { tivo }\end{array}$ & $\begin{array}{l}\text { Identificar fatores asso- } \\
\text { ciados a problemas de } \\
\text { saúde mental em crian- } \\
\text { ças/adolescentes. }\end{array}$ \\
\hline
\end{tabular}


(Continua)

\begin{tabular}{|c|c|c|c|}
\hline Ano & Título & $\begin{array}{l}\text { Tipo de } \\
\text { estudo }\end{array}$ & Objetivo \\
\hline 2010 & $\begin{array}{l}\text { Violência, depen- } \\
\text { dência química e } \\
\text { transtornos men- } \\
\text { tais em presidiá- } \\
\text { rios. }\end{array}$ & $\begin{array}{l}\text { Revisão } \\
\text { de litera- } \\
\text { tura }\end{array}$ & $\begin{array}{l}\text { Analisar a relação entre } \\
\text { violência, dependência } \\
\text { química e transtornos } \\
\text { mentais na população } \\
\text { carcerária masculina. }\end{array}$ \\
\hline 2010 & $\begin{array}{l}\text { Problemas de saú- } \\
\text { de mental na ado- } \\
\text { lescência: caracte- } \\
\text { rísticas familiares, } \\
\text { eventos traumáti- } \\
\text { cos e violência. }\end{array}$ & $\begin{array}{l}\text { Quantita- } \\
\text { tivo }\end{array}$ & $\begin{array}{l}\text { Identificar as situações } \\
\text { individuais, familiares e } \\
\text { contextuais associadas às } \\
\text { manifestações de desor- } \\
\text { dens emocionais em ado- } \\
\text { lescentes estudantes do } \\
\text { ensino médio da região } \\
\text { metropolitana de Porto } \\
\text { Alegre. }\end{array}$ \\
\hline 2010 & $\begin{array}{l}\text { Comportamento } \\
\text { violento, gênero e } \\
\text { psicopatologia. }\end{array}$ & $\begin{array}{l}\text { Revisão } \\
\text { de litera- } \\
\text { tura }\end{array}$ & $\begin{array}{l}\text { Estabelecer uma relação } \\
\text { entre comportamento } \\
\text { violento, gênero e psico- } \\
\text { patologia. }\end{array}$ \\
\hline 2011 & $\begin{array}{l}\text { Violência no tra- } \\
\text { balho em pronto } \\
\text { socorro: implica- } \\
\text { ções para a saúde } \\
\text { mental dos traba- } \\
\text { lhadores. }\end{array}$ & $\begin{array}{l}\text { Quanti- } \\
\text {-qualita- } \\
\text { tivo }\end{array}$ & $\begin{array}{l}\text { Analisar as violências so- } \\
\text { fridas por trabalhadores } \\
\text { de saúde de um hospital } \\
\text { público de pronto socor- } \\
\text { ro e as suas implicações } \\
\text { na saúde mental desses } \\
\text { profissionais. }\end{array}$ \\
\hline 2012 & $\begin{array}{l}\text { Violência e saúde } \\
\text { mental: os termos } \\
\text { do debate. }\end{array}$ & $\begin{array}{l}\text { Revisão } \\
\text { de litera- } \\
\text { tura }\end{array}$ & $\begin{array}{l}\text { Revisar a literatura e dis- } \\
\text { cutir sobre as repercus- } \\
\text { sões do fenômeno da vio- } \\
\text { lência no campo da saúde } \\
\text { mental. }\end{array}$ \\
\hline 2013 & $\begin{array}{l}\text { Violência e sofri- } \\
\text { mento mental em } \\
\text { homens na atenção } \\
\text { primária à saúde. }\end{array}$ & $\begin{array}{l}\text { Quantita- } \\
\text { tivo }\end{array}$ & $\begin{array}{l}\text { Analisar a associação en- } \\
\text { tre agravos à saúde men- } \\
\text { tal masculina episódios } \\
\text { de violência sofrida. }\end{array}$ \\
\hline 2013 & $\begin{array}{l}\text { Aspectos psicoló- } \\
\text { gicos de mulheres } \\
\text { que sofrem violên- } \\
\text { cia sexual. }\end{array}$ & $\begin{array}{l}\text { Revisão } \\
\text { de litera- } \\
\text { tura }\end{array}$ & $\begin{array}{l}\text { Considerar a posição } \\
\text { que é dada a elas ao lon- } \\
\text { go da história e buscar } \\
\text { compreender a dinâmica } \\
\text { psíquica que o estupro } \\
\text { envolve, assim como suas } \\
\text { marcas e consequências } \\
\text { psicológicas. }\end{array}$ \\
\hline
\end{tabular}

\begin{tabular}{|c|c|c|c|}
\hline Ano & Título & $\begin{array}{l}\text { Tipo de } \\
\text { estudo }\end{array}$ & Objetivo \\
\hline 2013 & $\begin{array}{l}\text { Ansiedade e de- } \\
\text { pressão em mulhe- } \\
\text { res vítimas de vio- } \\
\text { lência doméstica. }\end{array}$ & $\begin{array}{l}\text { Quantita- } \\
\text { tivo }\end{array}$ & $\begin{array}{l}\text { Avaliar o nível de ansie- } \\
\text { dade e depressão em } \\
\text { mulheres vítimas da vio- } \\
\text { lência doméstica, além de } \\
\text { caracterizar os tipos de } \\
\text { violência sofrida, tipo de } \\
\text { vínculo com o agressor e } \\
\text { dados sociodemográficos } \\
\text { das vítimas. }\end{array}$ \\
\hline 2013 & $\begin{array}{l}\text { Vitimização de } \\
\text { doentes mentais. }\end{array}$ & $\begin{array}{l}\text { Revisão } \\
\text { de litera- } \\
\text { tura }\end{array}$ & $\begin{array}{l}\text { Realizar revisão sistemá- } \\
\text { tica sobre a ocorrência } \\
\text { e fatores associados à } \\
\text { vitimização de doentes } \\
\text { mentais. }\end{array}$ \\
\hline 2014 & $\begin{array}{l}\text { A gente vive equi- } \\
\text { librando pratos: } \\
\text { olhares sobre a } \\
\text { violência que inter- } \\
\text { roga a rede pública } \\
\text { de saúde mental } \\
\text { do município do } \\
\text { Rio de Janeiro. }\end{array}$ & $\begin{array}{l}\text { Quantita- } \\
\text { tivo }\end{array}$ & $\begin{array}{l}\text { Caracterizar a rede de } \\
\text { saúde mental do muni- } \\
\text { cípio do Rio de Janeiro } \\
\text { e compreender os cami- } \\
\text { nhos, práticas e discursos } \\
\text { voltados à atenção presta- } \\
\text { da às pessoas em situação } \\
\text { de violência que chegam } \\
\text { a esses serviços. }\end{array}$ \\
\hline 2015 & $\begin{array}{l}\text { Violência domésti- } \\
\text { ca e risco para pro- } \\
\text { blemas de saúde } \\
\text { mental em crianças } \\
\text { e adolescentes. }\end{array}$ & $\begin{array}{l}\text { Quantita- } \\
\text { tivo }\end{array}$ & $\begin{array}{l}\text { Determinar a prevalência } \\
\text { dos problemas de saú- } \\
\text { de mental em crianças } \\
\text { e adolescentes vítimas } \\
\text { de violência doméstica e } \\
\text { analisar fatores de risco e } \\
\text { de proteção para o desen- } \\
\text { volvimento de psicopato- } \\
\text { logias nesses sujeitos. }\end{array}$ \\
\hline 2015 & $\begin{array}{l}\text { Violência sexual: } \\
\text { narrativas de mu- } \\
\text { lheres com trans- } \\
\text { tornos mentais no } \\
\text { Brasil. }\end{array}$ & $\begin{array}{l}\text { Qualita- } \\
\text { tivo }\end{array}$ & $\begin{array}{l}\text { Compreender o impacto } \\
\text { da violência sexual so- } \\
\text { frida por mulheres com } \\
\text { transtornos mentais a } \\
\text { partir de autorrelato de } \\
\text { suas experiências. }\end{array}$ \\
\hline
\end{tabular}

\section{DISCUSSÃO}

O presente estudo objetivou discutir sobre os imbricamentos existentes entre o fenômeno da violência e o campo da saúde mental, bem como investigar o fenômeno violência e sua relação com a produção de sofrimento psíquico; verificar a relação existente entre o cometimento da violência e sua causalidade manifestada 
pela presença de transtornos mentais e uso de drogas e ainda sobre as principais formas de vitimização sofridas por portadores de sofrimento mental.

Assim, para o alcance dos mesmos, os resultados encontrados permitiram emergir três categorias que serão apresentadas e discutidas a seguir, a saber: violência e a produção de sofrimento psíquico; os transtornos mentais, o uso de drogas e sua relação com a violência e, por fim, processos de vitimização sofridos por portadores de transtornos mentais.

\section{A VIOLÊNCIA E A PRODUÇÃO DE SOFRIMENTO PSÍ- QUICO}

Nesta categoria discutiremos sobre a violência e sua relevância como um dos fatores responsáveis por produzir sofrimento psíquico e/ou transtornos mentais.

Albuquerque, Barros e Schraiber, ${ }^{8}$ recorrem a Dejours sobre a definição de sofrimento mental ou psíquico como uma vivência subjetiva intermediária entre a doença mental descompensada e o conforto ou bem-estar psíquico, sendo um mal-estar que se expressa via angústia, preocupação, ansiedade, tensão e desânimo que não necessariamente é caracterizado como transtorno mental em sentido estrito da nosografia médica, e podendo ser considerado mais como desequilíbrio psíquico9. Já os transtornos mentais abarcam perfis psicopatológicos nas quais as alterações mentais já evidenciadas se traduzem em diagnósticos ${ }^{8}$.

Vários motivos influenciam no surgimento de problemas de saúde mental ao longo do desenvolvimento humano, incluindo aspectos sociais, biológicos e psicológicos. São diversos os fatores de risco, caracterizados como um fator ou evento que aumenta a probabilidade da ocorrência de determinada situação ou desfecho ${ }^{10}$. Torna-se importante discorrer sobre os possíveis fatores de risco para que seja possível o planejamento de intervenções e a possibilidade de diminuição dos agravos.

Fatori et al., na realização de um levantamento bibliográfico acerca de pesquisas nacionais envolvendo a investigação de fatores de risco para desenvolvimento de problemas de saúde mental (PSM) em crianças e adolescentes, constataram que há relação entre fatores de risco específicos e PSM na infância e adolescência, tais como: situações de vulnerabilidade, como pobreza e punição física; pais com transtornos mentais; mães vítimas de violência conjugal; e condições socioeconômicas desfavoráveis. Como se percebe a violência é um dos fatores que estabelece relação com a presença do sofrimento e transtornos mentais na infância e adolescência ${ }^{10}$.

Em um estudo com o objetivo de revisar a literatura epidemiológica sobre a prevalência de exposição à violência e sua associação com o desenvolvimento de problemas de saúde mental em países em desenvolvimento foi constatado que a exposição à violência está significativamente associada aos problemas de saúde mental em crianças e adolescentes, principalmente quando vinculada a outras desvantagens sociais ${ }^{11}$.

Estudo realizado em serviços especializados em atendimentos de famílias em situação de violação dos direitos, conveniados ao Centro de Referência Especializado da Assistência Social (CREAS) de uma cidade de São Paulo, evidenciou um índice elevado de problemas de saúde mental em crianças vítimas de violência doméstica. Os sintomas mais frequentes são referentes a problemas de conduta, depressão, ansiedade, dificuldade de relacionamento e problemas de atenção, como hiperatividade ${ }^{12}$.

Albuquerque, Barros e Schraiber, ao analisarem a associação entre agravos à saúde mental masculina $\mathrm{e}$ episódios de violência sofrida, encontraram que a prevalência de transtornos mentais é maior em homens solteiros e que utilizam substâncias psicoativas ${ }^{8}$. Foi constatado grande associação entre diagnósticos de transtorno mental e ocorrência de episódio de situações de violência em algum momento da vida, dentre estas destacam a violência física e/ou sexual recorrente ${ }^{8}$.

Ainda conforme este estudo os principais diagnósticos e ou formas de sofrimento eram expressos por meio de quadros de depressão, distúrbios do sono e nervosismo. ${ }^{8}$ Mostrou ainda que o uso abusivo de álcool e outras drogas estão fortemente associados a algum transtorno psiquiátrico na vida de muitos homens, assim, a relação entre sofrimento mental e experimentar situações de violência se apresenta também influenciada pelo uso de substâncias psicoativas ${ }^{8}$.

Em relação à violência contra a mulher, de acordo com autores a mulher é vítima de vários tipos de violência, tanto conjugal como no ambiente de trabalho 
e isso está fortemente associado a transtornos mentais comuns, uso abusivo de álcool e outras drogas além de ideação suicida. Segundo a pesquisa, crianças e mulheres estão mais expostos à violência sendo maioria desta praticada por cônjuges e pais ${ }^{11}$.

Infelizmente ainda existe uma cultura de que o homem tem necessidade de mostrar masculinidade e poder por meio do uso da violência ${ }^{13}$. Existe a banalização dos comportamentos agressivos dos homens que são importantes fatores de risco para causa de adoecimento mental, isso dificulta a visão das consequências de tais atos como necessidades de saúde ${ }^{13}$.

De acordo com Souza et al, entre as violências, as mulheres que sofrem violência sexual, apresentam índices mais graves de transtornos e sequelas psicológicas, como depressão, ansiedade, transtornos alimentares, distúrbios sexuais e distúrbios do humor ${ }^{13}$. Essa associação de violência sexual e transtorno do estresse pós-traumático incluem sintomas como a dissociação, congelamento e hipervigilância, podendo permanecer por um longo período ${ }^{13}$.

Para Bittar e Kohlsdorf, em relação às experiências na violência doméstica, essas deixam marcas na saúde física e mental e afetam a vida pública e a privada, causando um processo de autodesvalorização de si nas mulheres ${ }^{14}$. Foi constatado também que quase todas as mulheres entrevistadas informaram ter sofrido ameaças ou agressão psicológica ${ }^{14}$.

Outro aspecto relevante encontrado no mesmo estudo foi o relato da possibilidade de planos suicidas, destacando a relação entre as manifestações de depressão e ansiedade indicada na análise e diversos sentimentos como solidão, tristeza crônica, desamparo, irritação, culpa, desânimo, perda de apetite e de interesse sexual como consequência das situações de violência ${ }^{14}$.

Ainda sobre a relação entre violência doméstica e o adoecimento mental, para Morais as pesquisas têm mostrado que mulheres vítimas de violência, geralmente no âmbito doméstico, têm risco maior de adoecimento e de morbidade, porém essas mulheres continuam silenciando a violência, disfarçando a depressão, o medo, as fobias, o não enfrentamento e convivendo rotineiramente com o próprio carrasco ${ }^{15}$. Dentre as queixas psíquicas, os sintomas mais referidos pelas vítimas foram nervosis- mo, esquecimento, choro frequente, tontura, agressividade e compulsividade ${ }^{15}$.

Foi demonstrado ainda no estudo acima que a violência psicológica é a mais prevalente dentro do contexto doméstico e perpassa todas as outras formas de violência. Esta forma de violência acontece por meio das palavras, negligências, abusos sexuais ou como resultado da violência física ${ }^{15}$.

Outro contexto em que a violência aparece como um fator produtor de sofrimento psíquico e ocorrência de transtornos mentais é a área da saúde do trabalhador.

A violência no trabalho é capaz de causar alterações na saúde dos trabalhadores desfavorecendo a saúde psíquica e física dos profissionais. Dentre as principais consequências, destacam-se: vivência de desânimo, cansaço, ansiedade, depressão, pensamento suicida e hipersensibilidade $^{16}$. A preocupação e o sofrimento também são consequências da situação de violência, são também sentimentos prejudiciais, pois geram tensão e ansiedade podendo levar ao desenvolvimento de patologias ${ }^{16}$.

Barbosa, Souza e Freitas, em seu estudo, observaram que as populações mais pobres, com menor índice de escolaridade e desamparadas são as mais suscetíveis às diversas situações de violência. Como consequência, esta população mais vulnerável à violência também se encontra predisposta a apresentar vivências de sofrimento psíquico ou transtornos mentais ${ }^{17}$. A ocorrência de transtornos mentais neste contexto é um grande desafio por se tratar de processos complexos e por considerar que esses transtornos interferem em cada um, na capacidade cognitiva, na capacidade de se relacionar e tornando esses sujeitos mais suscetíveis a novos episódios de violência ${ }^{17}$.

Percebeu-se, portanto, por meio das pesquisas científicas e fontes bibliográficas que de fato existe uma relação importante entre a vivência das diversas situações de violência e como consequência a produção de sofrimento psíquico e ocorrência de transtornos mentais, o que se torna um grande desafio para o campo assistencial da saúde mental na medida em que intervir nas situações de sofrimento é também lidar com os fatores que estão intrinsecamente relacionados a ela.

\section{OS TRANSTORNOS MENTAIS, O USO DE DROGAS E SUA RELAÇÃO COM A VIOLÊNCIA}

A relação entre transtorno mental e violência ainda é bastante complexa gerando, apesar dos grandes 
avanços em relação à saúde mental, muitas dúvidas e discussões acerca do assunto em torno de questões culturais, sociais, éticas e políticas.

Essa associação, para a comunidade em geral, ainda evoca a ideia de o doente mental ser uma "pessoa louca"'. Um ato de violência ou violência grave cometido por uma pessoa com transtorno mental é relativamente raro, ou seja, são muito poucos os casos vistos pela sociedade, entretanto, quando ocorrem episódios e são apresentados pela mídia, o assunto volta a ser foco e toma uma grande repercussão pela sociedade sendo motivo de atenção e de debate ${ }^{6}$.

Os estudos que subsidiaram tal revisão de literatura $^{3}$, em sua maioria, propõem que ao contrário do que se pensa, é muito mais visto diariamente crimes serem cometidos por pessoas que não apresentam nenhum tipo de doença mental do que pessoas que sofrem de problemas mentais. Além disso, diversos estudos ${ }^{2,3,4,5,18,21}$ relatam que o portador de sofrimento mental tem uma probabilidade maior de sofrer violência do que propriamente provocá-las.

Para Teixeira et al., no entanto, novos estudos epidemiológicos acerca especificamente da esquizofrenia relatam que estes pacientes tendem a ser mais violentos que a população em geral ${ }^{6}$. Os indivíduos com transtornos psicóticos, pela sua condição psicopatológica, possuem potencial para desenvolverem comportamentos e atos violentos e isso se deve aos sintomas da doença como as alucinações e delírios que predispõem a esses atos, porém essa condição não deve ser generalizada ${ }^{6}$.

Apesar disso, menos de $10 \%$ da população possuem o diagnóstico de esquizofrenia o que torna as ocorrências de violência por este grupo pouco representativo no contexto geral ${ }^{6}$.

Um dos achados identificados nesta pesquisa foi que os transtornos mentais reduzem as diferenças de sexo quando se avalia sua relação com a ocorrência da violência. Para a população que comete violência sem a associação com transtornos mentais, o sexo masculino apresenta índices maiores e relação direta com tais ocorrências ${ }^{18}$. No entanto, quando a violência está associada à pessoa com transtorno mental é verificado que, tanto no homem quanto na mulher, o comportamento violento é aumentado pela presença de transtornos, sendo que aumentos mais significativos relativamente acontecem no sexo feminino ${ }^{18}$.

Outra questão que propusemos discutir e que é de suma importância é a relação drogas e violência. Embora estudos mostrem uma associação, ainda é um assunto muito complexo de ser discutido $0^{3,18,19}$.

Para Tavares e Almeida, a origem do comportamento violento é multifatorial, não estando até agora completamente esclarecida à relação entre violência e drogas já que o fenômeno violência pode estar relacionado a muitos tipos de fatores ou pode ser visto até mesmo como uma solução para determinadas situações. ${ }^{19}$ Ainda, segundo os mesmos autores, o consumo de álcool está entre os principais problemas de saúde pública no Brasil $^{19}$.

A alta prevalência do uso e dependência ao álcool faz desta droga a mais comumente associada aos episódios de violência que possuem relação com drogas ${ }^{19}$. As evidências apontam que as drogas podem aumentar a possibilidade de haver comportamento agressivo, porém isso não ocorre de forma generalizada, pois fatores individuais, sociais e culturais devem ser considerados ${ }^{18}$.

O consumo de substâncias psicoativas, o uso da cocaína, dos barbitúricos, das anfetaminas e/ou dos esteroides podem motivar atitudes e comportamentos violentos e isso pode ser uma consequência dos efeitos depressores, perturbadores ou estimulantes provocados no sistema nervoso central por estas substâncias ${ }^{19}$.

Tavares e Almeida ${ }^{19}$ analisam alguns estudos em que o consumo de drogas está presente em grande parte dos atos violentos, não como consequência, mas como agente causador. Nos casos de estupro e atentado ao pudor sua frequência é de $13 \%$ a $50 \%$. A relação entre a violência e a impossibilidade de controle, em situações de abuso de droga pode estar presente ${ }^{19}$.

Já em outro estudo, a partir de Ribeiro et al., foi possível observar grande associação do uso de drogas como consequência do sofrimento de violência, presente principalmente em adolescentes ${ }^{11}$. A exposição à violência é altamente prevalente e está consistentemente associada a transtornos mentais. As frustrações e a carência afetiva, irritabilidade presentes na rotina diária podem gerar depressão e ansiedade insuportáveis, que levam a buscar alívio de várias maneiras, entre elas por meio de atitudes autoagressivas, como o uso abusivo de drogas ${ }^{11}$. 
Em estudo feito por Albuquerque, Barros e Schraiber, $29,4 \%$ dos casos de sofrimento mental mostram associação com o uso de drogas. A prevalência dessa relação foi maior entre os homens solteiros e entre aqueles que faziam uso de substância psicoativa (álcool e/ou drogas ilícitas) ${ }^{8}$. Os resultados deste estudo comprovam os achados da literatura que aponta interação entre sofrimento mental e uso de alguma substância psicoativa. Pode-se assim, somado a algumas análises já feitas nesta pesquisa anteriormente, questionar e problematizar a possibilidade de haver relação entre a experiência de sofrimento mental, o uso de drogas e a ocorrência de violência .

Em estudo com adolescentes, realizado por Benetti et al. ${ }^{20} \mathrm{O}$ mesmo procurou estabelecer uma relação entre a saúde mental, uso de drogas e violência. Como resultado desta pesquisa, a adolescência mostrou-se como um grupo etário vulnerável para o uso de drogas, ocorrência de transtornos mentais tais como a depressão, transtornos de conduta, transtornos alimentares e transtornos relacionados ao uso de drogas, cometimento de delitos e sofrimento de violência. A vulnerabilidade está diretamente interligada por um fator que influencia o outro ${ }^{20}$.

Assim, para finalizar, a partir da literatura estudada, verificou-se que embora as evidências estatísticas e empíricas indiquem a existência de uma relação entre crime violento e psicose ou uso de drogas, isto apenas representa uma pequena parte da violência ocorrida na comunidade.

Conforme conclui Delgado, em sua análise sobre a relação entre transtornos mentais e violência, o reducionismo da interpretação de tais fenômenos pela vertente da psiquiatrização encontrará sua crítica consequente na análise da multidimensionalidade do evento. A ideologia de mão dupla da psiquiatrização do crime e criminalização da loucura ressurge sempre em tais momentos traumáticos, sendo um desafio do campo da saúde mental o esforço de interpretação aprofundada da complexidade do fenômeno ${ }^{3}$. Há assim, uma insuficiência empírica da associação crime e loucura, presente no imaginário social e cultural.

No Brasil, especificamente, a violência e a criminalidade têm intensa associação com condições socioe- conômicas, assim o percentual dos crimes associados a transtornos mentais graves é bem pequeno ${ }^{6}$. Portanto, apenas uma pequena parcela da violência deve ser atribuída a pacientes psicóticos, mais especificamente aos sujeitos com esquizofrenia ou com outros transtornos mentais graves e a dependência química.

\section{PROCESSOS DE VITIMIZAÇÃO SOFRIDOS POR PORTA- DORES DE TRANSTORNOS MENTAIS}

A partir do processo de desinstitucionalização, os pacientes com transtornos mentais graves passaram a integrar e fazer parte da comunidade, com isso surgiu uma preocupação em relação à violência. Socialmente, algumas questões emergiram interrogando sobre os riscos que alguns pacientes com transtornos mentais graves podem oferecer à comunidade e também os riscos desses indivíduos serem vítimas de violência ${ }^{6}$.

Autores referem que não se pode estabelecer uma relação de causa ou consequência entre transtornos mentais e violência, uma vez que a literatura demonstra que, por ora, ser vítima de violência é um fator precursor de sofrimento e ou doença mental, bem como ser portador de transtornos mentais é uma condição de risco para tornar-se vítima de ato violento ${ }^{11}$.

Evidenciando que, ao contrário do que o estigma de periculosidade que permeia a identidade do portador de transtorno mental, de acordo com dados estatísticos, as taxas afirmam que esses indivíduos apresentam maior tendência a serem vítimas de atos violentos do que a cometê-los ${ }^{21}$.

O que ocorre é que muitas vezes esses indivíduos estão inseridos em uma realidade que corrobora com a perpetuação da violência, como a pobreza, o isolamento social, o desemprego, os abusos de substâncias, os relacionamentos conflituosos e a ausência de um ambiente protegido, tendo como fatores agravadores o uso de substâncias, a idade jovem, o sexo masculino, a sintomatologia, a história recente de perpetração da violência, o passado criminal e a ausência de moradia fixa ${ }^{21}$. Assim, é inadequado justificar o ato violento pelo diagnóstico psiquiátrico.

O processo de vitimização se dá quando o indivíduo é vítima de qualquer ato agressivo. A vitimização 
pode ocorrer por duas vias: a violenta e a não violenta. A violenta está relacionada a assassinato, aos atos de agressão grave, ferido com arma de fogo, branca ou qualquer objeto, quando é forçado a realizar atos sexuais ${ }^{21}$. Já a forma não violenta dar-se-á quando a vítima é submetida a qualquer comportamento agressivo, como ser ameaçado de morte, ameaça de abuso sexual, estrangulado ou esbofeteado, mordido ${ }^{21}$.

Quando esse processo de vitimização se dá com portadores de doença e ou sofrimento mental, pode agravar os sintomas psiquiátricos pré-existentes, acarretando a maior busca pelo serviço de saúde, bem como o aumento de internações e comprometimento da qualidade de vida desses indivíduos ${ }^{21}$.

Para Passos, Stumpf e Rocha, os indivíduos portadores de transtornos mentais graves constituem um grupo particularmente vulnerável à vitimizaçãa $0^{21}$. Essa maior suscetibilidade a crimes violentos deve-se ao comprometimento de suas funções cognitivas e às condições de vida desses indivíduos. Entre os atos violentos a que são vítimas pode-se destacar a agressão, estupro, assalto, roubo e assassinato ${ }^{21}$.

O termo "doença mental grave" refere-se a um subgrupo de transtornos psiquiátricos: transtornos psicóticos e transtornos afetivos maiores que são caracterizados por sintomas cognitivos, comportamentais e emocionais graves e persistentes, que causam prejuízos ao funcionamento diário ${ }^{21}$.

Dessa forma, contrariamente ao estereótipo de periculosidade associado ao portador de transtorno mental grave, esses indivíduos apresentam maiores taxas de vitimização que de perpetração de atos violentos, isto é, são mais vítimas que algozes ${ }^{21}$. Portanto, a de se reconhecer que é necessário promover a conscientização por meio da informação à sociedade sobre os verdadeiros riscos sofridos pelos portadores de sofrimento mental e desmistificar a ideia de periculosidade associada a estes casos promovendo assim a reinserção dos portadores de sofrimento mental contribuindo para sua qualidade de vida.

\section{CONSIDERAÇÕES FINAIS}

O estudo pode evidenciar que existe uma relação importante entre a vivência das diversas situações de violência e, consequentemente, a produção de sofrimento psíquico e ocorrência de transtornos mentais. Seja ela sofrida por crianças, adolescentes, adultos ou idosos, em casa ou no trabalho, o qual torna os sujeitos acometidos suscetíveis ao sofrimento.

Além disso, os estudos mostraram que os indivíduos portadores de transtornos mentais graves constituem um grupo particularmente vulnerável à vitimização de diversas formas de violência. Contrariamente ao estereótipo de periculosidade associado ao portador de transtorno mental grave, esses indivíduos apresentam maiores taxas de vitimização que de perpetração de atos violentos, isto é, são mais vítimas que algozes.

Concluindo, há de se reconhecer que é necessário, portanto, promover conscientização à sociedade por meio de informação sobre os verdadeiros riscos sofridos pelos portadores de sofrimento mental e desmistificar a ideia de periculosidade associada a estes casos a fim de promover a reinserção dos portadores de sofrimento mental e contribuir para sua qualidade de vida.

\section{REFERÊNCIAS}

1. Brasil. Ministério da Saúde. Cadernos de Atenção à Saúde. Saúde Mental. Política nacional de atenção básica. Brasília: Ministério da Saúde; 2010. p.27

2. Bertolote JM. Violência e saúde mental: como podemos fazer parte da solução? Rev Bras Psiquiatria. 2009; 31(2): 39-40.

3. Delgado PGG. Violência e saúde mental: os termos do debate. Revista O Social em Questão, Rio de Janeiro. 2012; 15 (28): 187-98.

4. Valadares FC, Souza ER. A gente vive equilibrando pratos: olhares sobre a violência que interroga a rede pública de saúde mental do município do Rio de Janeiro. Saúde Soc., São Paulo. 2014; 23 (3): 841-54.

5. Long PW. Violência e pacientes violentos. Neuropsiconews. 2000; 18: 07-13.

6. Teixeira EH, Pereira MC, Rigacci R, Dalgalarrondo P. Esquizofrenia, psicopatologia e crime violento: uma revisão das evidências empíricas. J Bras Psiquiatr. 2007; 56 (2): 127-33.

7. Marconi MA, Lakatos EM. Metodologia do trabalho 
científico. São Paulo: Atlas, 1992. 4. ed. p. 43-44.

8. Albuquerque FP, Barros CRS, Schraiber LB. Violência e sofrimento mental em homens na atenção primária a saúde. Rev Saúde Pública. 2013; 47(3): 531-9.

9. Dejours C, Abdouchelli E, Jayet C. Psicodinâmica do trabalho: contribuições da escola dejouriana à análise da relação prazer, sofrimento e trabalho. São Paulo: Atlas; 1994.

10. Fatori de Sá DG, Bordin IAS, Martin D, Paula CS. Fatores de Risco para Problemas de Saúde Mental na Infância/Adolescência. Psicologia: Teoria e Pesquisa. [Internet] 2010; [Acesso em 2016 nov 3] 26(4): 64352. Disponível em: $<$ http://www.scielo.br/pdf/ptp/ v26n4/08.pdf $>$.

11. Ribeiro WS, AndreoliI SB, FerrilCP, PrinceII M, MariJJ. Exposição à violência e problemas de saúde mental em países em desenvolvimento: uma revisão da literatura. Revista Brasileira de Psiquiatria. 2009;31 (2): $49-57$.

12. Hildebrand NA, Celeri EHRV, Morcillo AM, ZanolliML.Violência doméstica e risco para problemas de saúde mental em crianças e adolescentes. Psicol. Reflex. Crit., Porto Alegre. [Internet] 2015; [Acesso em 2016 nov 3] 28(2):213-21. Disponível em:<http:// www.scielo.br/scielo.php?script $=$ sci_arttext\&pi$\mathrm{d}=$ S0102-79722015000200213\&lng $=$ en\&nrm $=\mathrm{i}$ so>.

13. Souza FBC, Drezett J, Meirelles AC, Ramos DG. Aspectos psicológicos de mulheres que sofrem violência Sexual. Reprod. clim. [Internet] 2013; [Acesso em 2016 out 30] 27(3):98-103. Disponível em: <http:// recli.elsevier.es/pt/aspectos-psicologicos-mulheres-que sofrem/articulo/S141320871300006X/>.

14. Bittar D, Kohlsdorf M. Ansiedade e depressão em mulheres vítimas de violência doméstica. Psicol. Argum. Curitiba. [Internet] jul./set 2013; [Acesso em 2016 out 30] 31(74): 447-56. Disponível em: $<$ http://www2.pucpr.br/reol/pb/index.php/pa?$\mathrm{dd} 1=12236 \& \mathrm{dd} 99=$ view $\& \mathrm{dd} 98=\mathrm{pb}>$.

15. Morais AC. Depressão em mulheres vítimas de violência doméstica.Dissertação (Mestrado) - Universidade Federal da Bahia, Escola de Enfermagem - Salvador, 2009. [Acesso em 2016 out 30]. Disponível em:
< http://www.repositorio.ufba.br:8080/ri/bitstream/ ri/11425/1/Disserta\%C3\%A7\%C3\%A3o_Enf_Ariane\%20Cedraz\%20Morais.pdf $>$.

16. Pai DD. A violência no trabalho em pronto socorro: implicação para a saúde mental dos trabalhadores. 2011. 218 f. Tese (Programa de Pós graduação em enfermagem) - Universidade Federal do Rio Grande do Sul, Porto Alegre, 2011. Disponível em: $\quad<$ http://www.lume.ufrgs.br/bitstream/handle $/ 10183 / 37115 / 000819751$.pdf?sequence $=1>$.

17. Barbosa JAG,Souza MCMR, Freitas MIF. Violência sexual: narrativas de mulheres com transtornos mentais no Brasil. Rev Panam Salud Publica. [Internet] 2015; [Acesso em 2016 out 30] 37(4/5):273-8. Disponível em: < https://www.scielosp.org/article/ssm/ content/raw/?resource_ssm_path $=/$ media/assets/ rpsp/v37n4-5/v37n4-5a13.pdf $>$.

18. Valença AM, Nascimento I, Mecler K, Freire R, Mezzasalma MA. Comportamento violento, gênero e psicopatologia. Rev. Latinoam. Psicopat. Fund, São Paulo. 2010; 13 (2): 238-52.

19. Tavares GP, Almeida RMM. Violência, dependência química e transtornos mentais em presidiários. Estudos de Psicologia I CampinasI. 2010; 27 (4): 545-52.

20. Benetti SPC, Ramires VRR, Schneider AC, Rodrigues APG, TremarinD.Problemas de saúde mental na adolescência: características familiares, eventos traumáticos e violência. Psico-USF. 2010; 15(3); 321-32.

21. Passos AF, Stumpf BP, Rocha FL. Vitimização de doentes mentais. Rev. psiquiatr. clín., São Paulo. [Internet] 2013; [Acesso em 2016 out 31] 40 (5): 191-6. Disponível em <http://www. scielo.br/scielo.php?script $=$ sci_arttext\&pi$\mathrm{d}=$ S0101-60832013000500004\&lng $=$ en\&nrm $=\mathrm{i}-$ so $>$.

Recebido em: 16/03/2018 Aceito em: 20/08/2018 